\title{
Jalili syndrome
}

INSERM

\section{Source}

INSERM. (1999). Orphanet: an online rare disease and orphan drug data base. Jalili syndrome. ORPHA:1873

Jalili syndrome is characterized by the association of amelogenesis imperfecta (Al; see this term) and cone-rod retinal dystrophy (CORD; see this term). 